\title{
Erratum: Effects of the wide-body suspension bridge auxiliary structure on flutter characteristics by CFD
}

\author{
Zhijun Ni ${ }^{1}$, Cong Zhang ${ }^{2}$, Liangliang Zhang ${ }^{3}$, Lianjie Liu ${ }^{4}$ \\ ${ }^{1,2,3,4}$ School of Civil Engineering, Chongqing University, Chongqing, 400045, China \\ ${ }^{1}$ Chongqing Architectural Design Institute of China, Chongqing, 400045, China \\ ${ }^{3}$ City College of Science and Technology, Chongqing University, Chongqing, 400045, China \\ ${ }^{3}$ Corresponding author

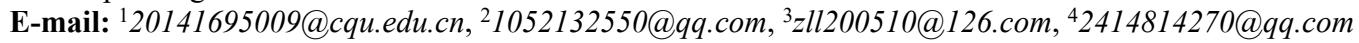 \\ DOI https://doi.org/10.21595/vp.2019.21117 \\ Check for updates
}

Copyright $(\mathrm{C} 2019$ Zhijun Ni, et al. This is an open access article distributed under the Creative Commons Attribution License, which permits unrestricted use, distribution, and reproduction in any medium, provided the original work is properly cited.

\section{Publisher's note regarding paper}

Ni Zhijun, Zhang Cong, Zhang Liangliang, Liu Lianjie Effects of the wide-body suspension bridge auxiliary structure on flutter characteristics by CFD. Vibroengineering PROCEDIA, Vol. 28, 2019, p. 223-229, https://doi.org/10.21595/vp.2019.21080.

\section{The description of the correction}

The corresponding author number was set incorrectly in the paper finally approved (after the acceptance) by the authors.

Incorrect corresponding author number:

${ }^{1}$ Corresponding author

Revised corresponding author number:

${ }^{3}$ Corresponding author 